\title{
Effects of colored zirconia surface treatment on the bond strength of veneering ceramics
}

\author{
SA-Hak Kim ${ }^{1}$, Chong-Kyen Kim² \\ ${ }^{1}$ Department of Dental Laboratory Technology, Kyungdong University, Wonju, Korea \\ ${ }^{2}$ Department of Hotel Management, Kyungdong University, Goseong, Korea
}

\section{Article Info}

Received December 5, 2021

Revised December 15, 2021

Accepted December 17, 2021

\section{Corresponding Author}

SA-Hak Kim

Department of Dental Laboratory Technology, Kyungdong University, 815 Gyeonhwonro, Munmak-eup, Wonju 26495, Korea E-mail: dksh@kduniv.ac.kr

https://orcid.org/0000-0002-5893-6413

*This research was supported by Kyungdong University Research Fund, 2021.
Purpose: In this study, when the etching treatment method, which is a chemical surface treatment method, is applied to colored zirconia, the shear bond strength between the veneering ceramic material and colored zirconia is compared with that without surface treatment, and the fracture type is observed to evaluate the etching treatment effect of colored zirconia.

Methods: Experiments were conducted after dividing the study sample into two groups, which are the zirconia control group without surface treatment using colored zirconia blocks (without etching zirconia, NZC group) and the zirconia group treated with a commercially available etching solution (etching liquid zirconia, EZC group).

Results: The mean shear bond strength of the NZC group was $20.31 \pm 2.32 \mathrm{Mpa}$, and that of the EZC group was $25.95 \pm 2.34 \mathrm{Mpa}$, and the difference between these two values was statistically significant $(p<0.05)$. Further, the surface roughness $R a$ value was higher in the EZC group than in the NZC group. In the fracture pattern, cohesive fractures were dominant, and adhesive fractures and cohesive fractures were mixed.

Conclusion: The bond strength was significantly higher in the group treated with colored zirconia. The fracture pattern was mostly cohesive failure in the group not treated with etching and changed to mixed failure as the etching treatment progressed.

Key Words: Bond strength, Colored zirconia, Etching, Zirconia

\section{INTRODUCTION}

The most suitable way to realize high esthetics is an all-ceramic crown that does not use a metal that blocks light. Metalfree restoration using new all ceramic materials is currently being used as a variety of crown restoration methods with good biocompatibility and improved physical properties, as well as adhesive resin cement and CAD/CAM (computer-aided design/ computer-aided manufacturing) devices have been developed.

Like traditional all-ceramic crowns, the zirconia all-ceramic crown has a two-layer structure consisting of a zirconia lower core and a ceramic upper structure. This two-layer structure was first introduced by McLean and Hughes in 1965 for an allceramic crown using an alumina-reinforced core [1]. Although aesthetic, the risk of fracture at the bonding interface with the electrical ceramic and the low bonding force between the ce- ramic restoration and the resin cement This problem is pointed out.

Zirconia has a fracture strength of 700 800 Mpa, similar to metal, and is used in posterior ceramic tubes, anterior and posterior ceramic bridges, ceramic posts, implant abutments, implant bodies, and orthodontic brackets [2]. In particular, the precision and convenience of prosthesis fabrication using $\mathrm{CAD} / \mathrm{CAM}$ in dental areas are increasing, and the production of zirconia repair products using them is a factor of consideration, where mechanical, chemical, and biocompatibility are important in oral function [3,4].

The all-porcelain tube using a dental zirconia (Y-TZP, yttriastabilized tetragonal zirconia polycrystal) core has a structure similar to that of a metal ceramic tube, but the difference is that the inner core material is different. Since the color of dental zirconia is generally white, it is aesthetically superior 
to metal porcelain tubes even if the core is exposed after prolonged use [5].

The effects of the surface treatment of zirconia on the bonding strength with the veneering ceramic material and the mechanical strength of zirconia itself is still being discussed a lot, and in a number of studies, the surface treatment before veneering is the difference between the bonding strength and bonding between the veneering ceramic material and the zirconia core. It deals with the effects of bonding strength and quality of bonding.

In general, after fabricating a framework using a CAD/CAM system, one or more surface treatments are performed before veneering the ceramic material. Surface treatment methods can be divided into mechanical methods and chemical methods. Mechanical methods include air abrasion (aluminum oxide particle roughen), laser treatment, selective infiltration technique, hot etching solution, nano structured alumina coating, etc., and tribochemical silicacoating is also used. For chemical methods, a silane coupling agent is used. There is a surface treatment methods [6].

Although there are many different surface treatment methods, many studies have been reported on using hydrofluoric acid or etching agents in zirconia with low reactivity. Hydrofluoric acid is basically a colorless, irritating liquid that smokes in the air, is highly reactive, and reacts with almost all metals such as alkalis, alkaline earth metals, lead, zinc, and silver to form fluorides. Using this property of hydrofluoric acid, it can be expected to change the surface of zirconia, which does not react to various chemical solvents so far. In general, hydrofluoric acid used for surface treatment of white zirconia is usually diluted by $48 \%$, but there is always a risk because it exists in a gaseous state in the air.

Although zirconia core is more aesthetic than metal, it is too white and opaque, so it is difficult to realize the aesthetics of natural teeth. Therefore, a colored zirconia core was developed for the tonal harmonization of restorations. The advantage of the colored zirconia core is that it can reduce the thickness of the veneering ceramic material required to mask the color of the underlying structure, and it is not necessary to use a masking liner that can affect the bonding strength between the zirconia and the veneering ceramic material [7]. However, it has been reported that it has weaker bonding strength with veneering coatings than conventional white zirconia [8].
When making zirconia restoration products with CAD/CAM system, the volume change of zirconia that occurs during surface treatment and sintering affects the compatibility with veneering ceramics. Accordingly, many efforts have been made to increase the bonding force between the colored zirconia and the veneering ceramic material interface.

Therefore, this study compares and evaluates the shear bonding strength between the electric material and the colored zirconia when the chemical surface treatment method, the etching treatment method, is applied to the colored zirconia, and observes the fracture type to find out the etching treatment effect of the colored zirconia.

\section{MATERIALS AND METHODS}

\section{Experimental material}

\section{1) Experimental design}

In this study, the experiment was divided into two experimental groups: a zirconia control group without surface treatment using colored zirconia blocks (without etching zirconia, NZC group) and a zirconia group treated with a commercially available etching solution (etching liquid zirconia, EZC group) carried out. A total of 16 specimens were produced by making 8 specimens for each group, and all of the specimen production processes were performed by one skilled technician. Zirconia blocks (Luxen E2; Dentalmax, Seoul, Korea), etching liquid (Smart Etching 2; YESBIO, Seoul, Korea) and veneering ceramic (Vintage ZR A2B; Shofu, Tokyo, Japan) were used as the materials used (Table 1).

\section{2) Specimen making}

For the production of colored zirconia specimens, in order to obtain data by actual clinical process for the production of colored zirconia specimens, a rectangular standard was designed with a 3D program (Fusion 360; Autodesk, San Rafael, CA, USA) and saved as a STL file, and milled with dental CAD/CAM. The processed zirconia specimen was heated up to $1,490^{\circ} \mathrm{C}$. after 240 minutes in a sintering furnace dedicated to zirconia, and then slowly cooled after mooring at $1,490^{\circ} \mathrm{C}$ for 2 hours (Fig. 1).

After slow cooling, the specimens of the NZC group were cleaned with steam and stored for veneering the veneering porcelain. For the surface etching of the colored zirconia of 
Table 1. Materials used in this study

\begin{tabular}{lll}
\hline \multicolumn{1}{c}{ Materials } & \multicolumn{1}{c}{ Product } & Manufacture \\
\hline Zirconia block & Luxen E2 & Dentalmax, Seoul, Korea \\
Veneering ceramic & Vintage ZR A2B & Shofu, Tokyo, Japan \\
Etching liquid & Smart Etching 2 & YESBIO, Seoul, Korea \\
\hline
\end{tabular}
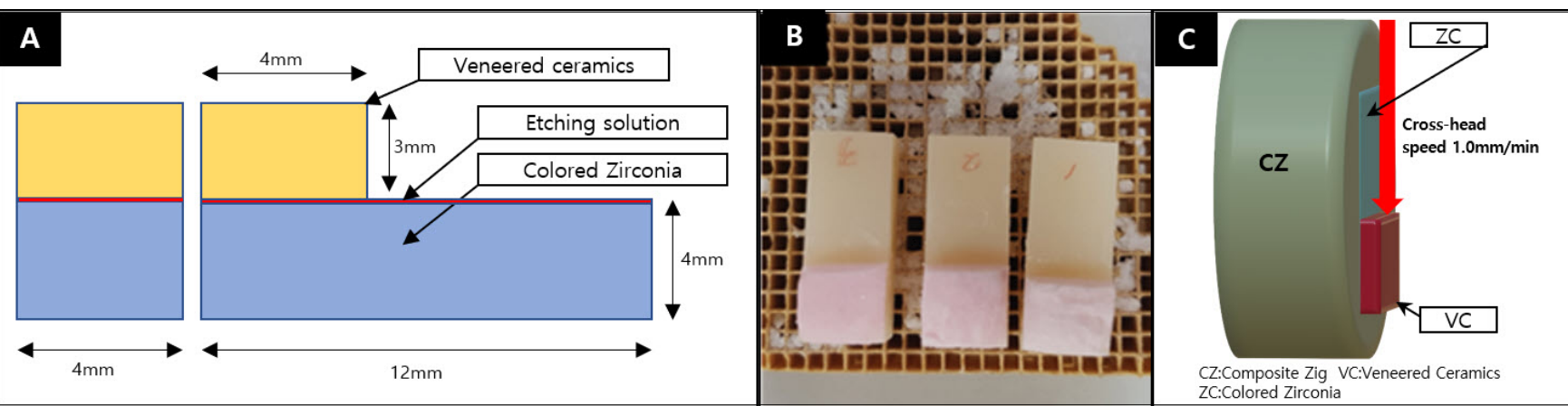

Figure 1. Fabrication of specimens and test. (A) Schematic diagram. (B) Final build up. (C) Measurement of shear bond strength.

Table 2. Firing schedule time for dental veneering ceramic

\begin{tabular}{|c|c|c|c|c|c|c|}
\hline & Drying & Preheating & Firing temperature & Cooling & Relief & VAC (level/hold) \\
\hline Time & \multirow[t]{3}{*}{$5 \sim 6 \mathrm{~min}$} & $1 \mathrm{~min}$ & $30 \mathrm{sec}$ & \multirow[t]{4}{*}{$2 \min$} & \multirow[t]{4}{*}{$2 \min$} & $10 \mathrm{sec}$ \\
\hline 1st Body & & $650^{\circ} \mathrm{C}$ & $920^{\circ} \mathrm{C}$ & & & $100 \%$ \\
\hline 2nd Body & & $650^{\circ} \mathrm{C}$ & $920^{\circ} \mathrm{C}$ & & & $100 \%$ \\
\hline Temperat & $\operatorname{ed~}\left(45^{\circ} \mathrm{C} /\right.$ & & & & & \\
\hline
\end{tabular}

the EZC group, according to the manufacturer's instructions, the colored zirconia specimens were placed in a commercially available Smart Etching 2 etching solution in a hot water bath at $80^{\circ} \mathrm{C}$. After heating the colored zirconia by immersion for 15 minutes, it was removed, washed with steam, and stored for build up of veneering ceramics.

\section{3) Build up of veneering ceramics}

After the etching treatment of the colored zirconia specimen was finished, the surface was cleaned of foreign substances using a steam cleaner (SESY 2014; SEKI, Seoul, Korea). For build up of veneering ceramics, the primary wash dentin is mixed with distilled water and sintered in an exclusive kiln (Austromat D4 press; Dekema, Freilassing, Germany) according to the manufacturer's instructions (Table 2). Then, the secondary dentin powder is veneered to a thickness of $3 \mathrm{~mm}$ to form a final rectangular parallelepipeds. was made with The finished specimen for measuring shear bond strength was prepared so that the veneer ceramic specimen was located in the center by using the corrective resin (Ortho-Jet; Lang Dental, Wheeling,
IL, USA) in an acrylic cylinder with a diameter of $30 \mathrm{~mm}$ using the manufacturer's mixing ratio. The finished 16 specimens were placed in distilled water for conditions similar to the oral environment and stored at $37^{\circ} \mathrm{C}$ for 48 hours using a drying oven (DG400; Yamato Scientific, Tokyo, Japan), and then shear bonding strength was measured.

\section{4) Surface roughness measurement}

After processing the colored zirconia specimen with dental $\mathrm{CAD} / \mathrm{CAM}$ and sintering it, the surface roughness before and after the surface etching treatment was measured by using a surface rougher (SJ-400; Mitutoyo, Tokyo, Japan) at a feed rate of $0.5 \mathrm{~mm} / \mathrm{s}$ to $4.0 \mathrm{~mm}$ from the center. Each specimen was measured three times and the average value of the arithmetic mean roughness $(\mathrm{Ra})$ was recorded.

\section{5) Shear bond strength measurement}

The shear bond strength measurement was measured using a universal material tester (Instron 5966; Instron, Norwood, MA, USA) at a crosshead speed of $1.0 \mathrm{~mm} / \mathrm{min}$. After fixing 
the lower part of the resin block in which the colored zirconia specimen was embedded in the jig, a force parallel to the interface was applied so that fracture occurred at the bonding site of veneering ceramic material and the colored zirconia. The shear bond strength was calculated by measuring the maximum load $(\mathrm{N})$ at the time of fracture and dividing by the cross-sectional area of the veneering ceramic material.

\section{6) Observation of microstructure and fracture types}

Sixteen specimens with microstructures and fractures due to the colored zirconia etching treatment were classified with a magnifying glass and observed using a Scanning Electron $\mathrm{Mi}^{-}$ croscope S-3000H (Hitachi, Tokyo, Japan) to observe fracture types. When the veneering ceramic material is cleanly separated from the specimen, it is classified as adhesive failure, when fracture occurs in the veneering ceramic material or colored zirconia part, it is cohesive failure, and when adhesive and cohesive failures are mixed, it is classified into adhesive failure.

\section{7) Statistical analysis}

The average values of the shear bond strengths of colored zirconia and veneering porcelain, which were measured by

Table 3. Shear bond strength of the veneering ceramic to colored zirconia

\begin{tabular}{ccc}
\hline \multirow{2}{*}{ Group } & \multicolumn{2}{c}{ Shear bonding strength (MPa) } \\
\cline { 2 - 3 } & Mean & Standard deviation \\
\hline NZC & $20.31^{\mathrm{a}}$ & 2.32 \\
EZC & $25.95^{\mathrm{b}}$ & 2.34 \\
\hline
\end{tabular}

a,b Letters indicate statistical significance $(p<0.05)$ by Tukey's honestly significant difference test $(\alpha=0.05)$.

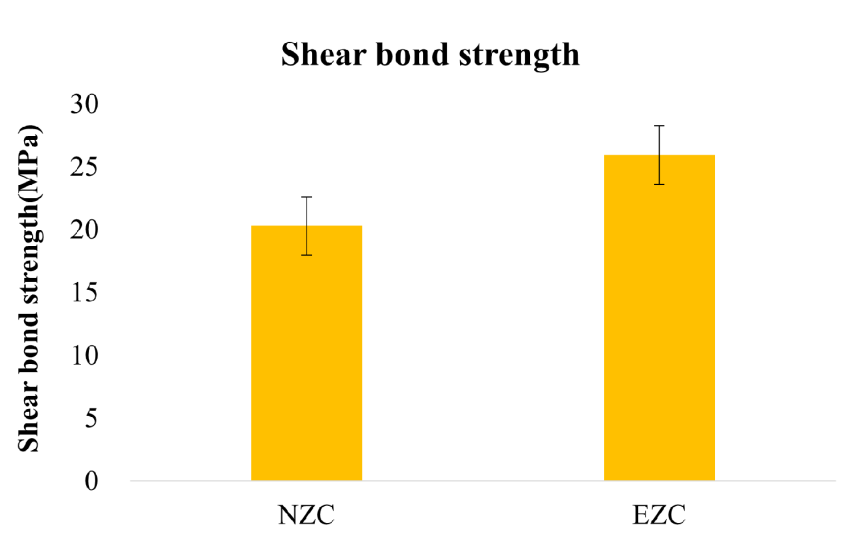

Figure 2. Results of between zirconia and veneering ceramic. NZC: without etching zirconia, EZC: etching liquid zirconia. dividing the maximum load by the cross-sectional area, were obtained, and an independent t-test was performed $(\mathrm{p}<0.05)$. In addition, the average value of surface roughness was also comparatively analyzed.

\section{RESULTS}

\section{Changes in shear bond strength according to etching treatment}

The average \pm standard deviation shear bond strength of NZC group without surface etching treatment was $20.31 \pm 2.32 \mathrm{Mpa}$, and the EZC group showed a shear bonding strength of 25.95 $\pm 2.34 \mathrm{Mpa}$. The average shear bond strength of the EZC group was higher than that of the NZC group, and as a result of the t-test, the difference depending on whether the surface was etched was statistically significant $(p<0.05$; Table 3 , Fig. 2$)$. The surface roughness showed a higher Ra value than the group treated with etching (Table 4, Fig. 3).

\section{Fracture pattern analysis}

The surface condition for etching treatment is shown in Fig. 4, and the condition after fracture is shown in Fig. 5. The fracture pattern of the specimen is shown in Fig. 6. Most of the fracture patterns of the NZC group that were not etched were cohesive fractures, and in the EZC group, most of the mixed

Table 4. Surface roughness values experimental groups

\begin{tabular}{ccc}
\hline Group & NZC & EZC \\
\hline Surface roughness (unit: $\mu \mathrm{m}$ ) & $0.78 \pm 0.13$ & $1.37 \pm 0.05$ \\
\hline
\end{tabular}

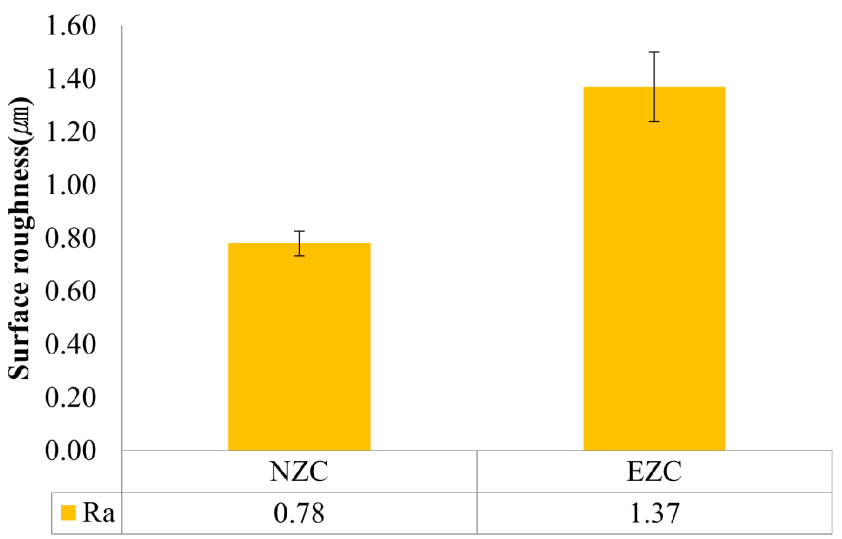

Figure 3. Results of surface roughness ( $R$ a) before and after etching treatment. NZC: without etching zirconia, EZC: etching liquid zirconia. 

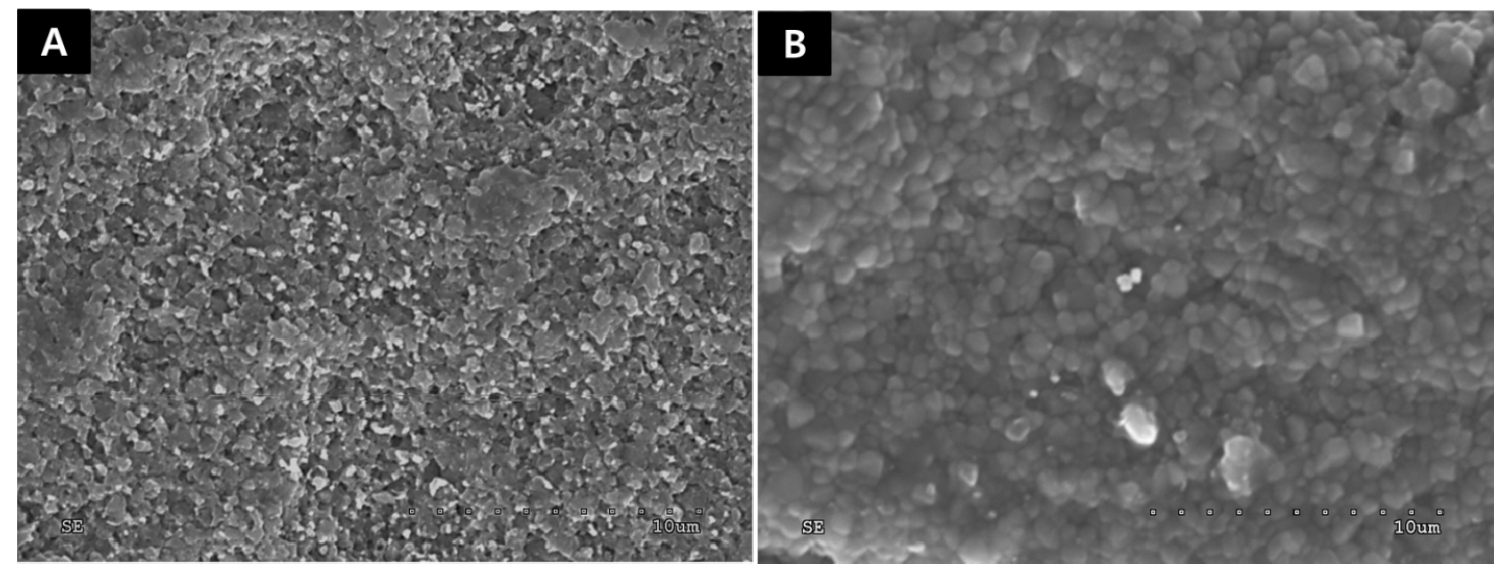

Figure 4. (A) Surface image after and (B) before etching treatment $(\times 5,000)$.

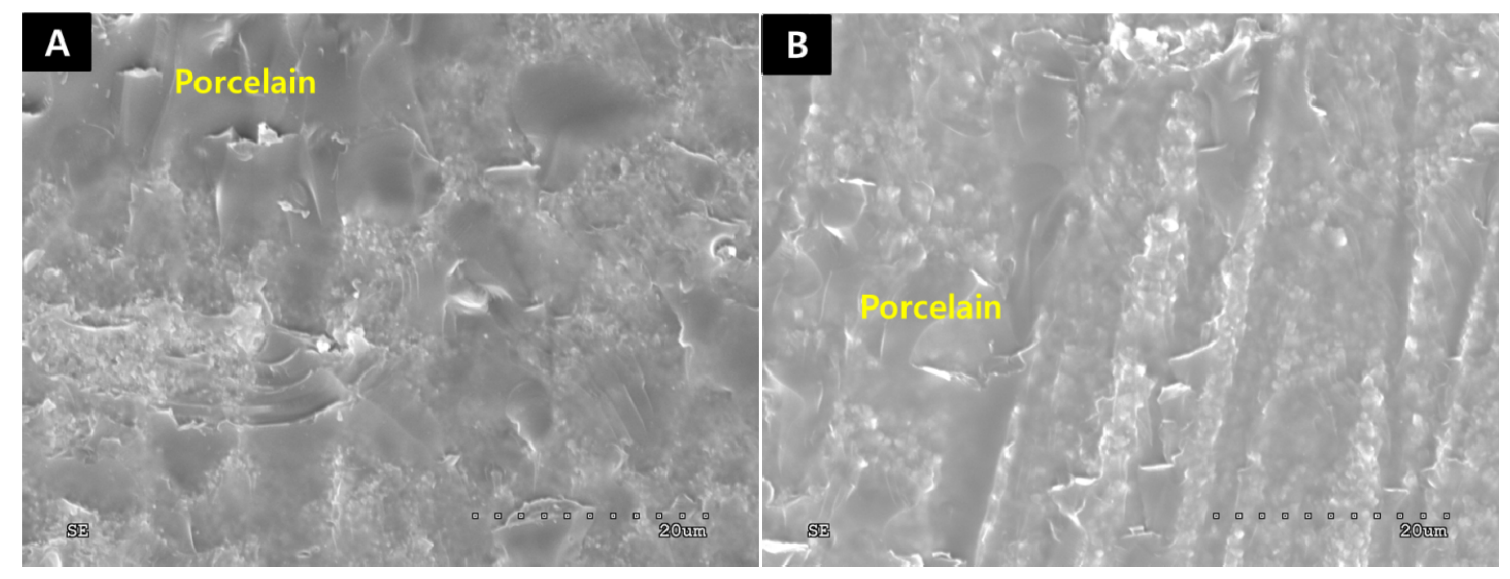

Figure 5. (A) Shear adhesive strength after and (B) before breaking state $(\times 2,000)$.
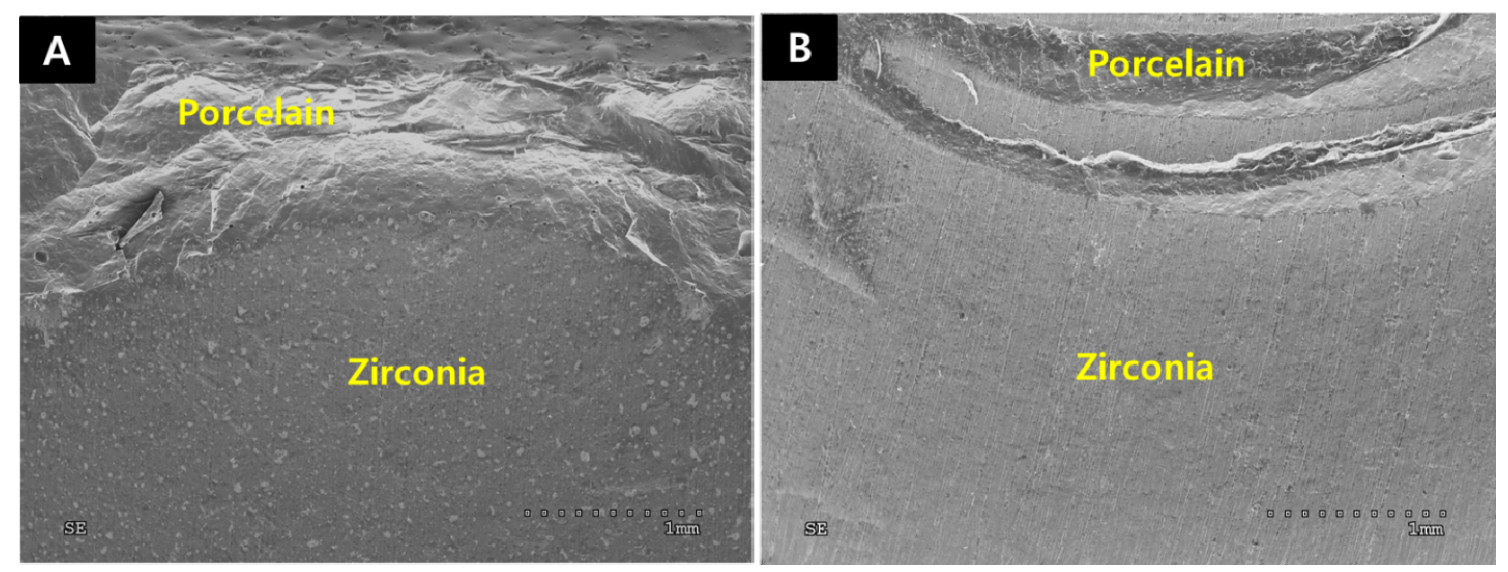

Figure 6. (A) Analysis of fracture patterns after and (B) before $(\times 30)$.

fractures that occurred simultaneously due to a mixture of adhesive and cohesive fractures were observed.

\section{DISCUSSION}

In order to success the zirconia conductive pipe formed of the high-strength zirconia lower core and the feldspar-based 
upper electronic coating, strength of the material itself is an important factor, and also coupling between the lower core and the upper electronic coating is important. Potiket and Chiche [9] reported that there was no difference in the fracture strength of metal ceramic crowns, alumina ceramic tubes, and zirconia ceramic tubes, indicating that the fracture strength of these ceramic restorations is determined by factors other than the properties of the underlying core material itself. It is estimated that the shear bonding strength between the lower core material and the upper electronic material has a great influence on the fracture strength [10].

Among the various cement that adheres zirconia restoration to teeth, cement, which is clinically selected in recent years, is resin cement with high deflection blockade and retention. When the bond between zirconia and resin cement is reliable, clinical success and long life can be expected [11]. This bonding is enhanced when effective micromechanical retention is achieved. Various surface treatment methods have been tried to obtain micromechanical holding force to reduce fracture between the veneering ceramic material and the zirconia interface as well as to enhance bonding strength between zirconia and resin cement [12].

Although such high-strength zirconia ceramics have been treated with the same surface treatment as traditional ceramics to obtain clinically important adhesion, Kosmac et al. [13] said that it may cause potential fractures that may occur during the use of the prosthesis, Phark et al. [14] said that it is not recommended to air sbrasion the zirconia surface, and Zarone et al. [15] said that acid treatment using hydrofluoric acid is effective only in dental materials containing $\mathrm{SiO} 2$, and has no silica phase in high-strength ceramics such as zirconia, so it is not effective.

Although white zirconia is more aesthetic than metal, it is too white and opaque. To enhance aesthetics, zirconia was developed by adding a metal oxide such as iron oxide to zirconia to give a natural color tone effect [8]. The greatest advantage of colored zirconia is that it can reduce the thickness of the upper veneering ceramics material required to shield the nonaesthetic white color of the lower core of zirconia [16]. For this effect, as a method of coloring zirconia for this effect, a metal pigment is added to the zirconia powder before or after the pressing of the cut block, or the cut framework is immersed in a dissolved dye, or a liner is applied to a sintered white frame- work. Various methods have been introduced, but for colored zirconia, the added pigment may affect the bonding strength between the zirconia and the upper veneering ceramic material [17].

In this study, a commercially available colored zirconia specimen was prepared to test the bonding strength with the upper veneering ceramic material due to the etching treatment, and shear bonding strength was tested using a universal testing machine. The purpose of this study is to find out how the etching treatment of colored zirconia affects the bonding strength between the upper veneering ceramic material and the lower colored zirconia, and to find out the fracture pattern and surface roughness.

As a result of the experiment, the shear bond strength results with and without etching treatment were found to be 20.31 $\mathrm{MPa}$ in the NZC group and $25.95 \mathrm{MPa}$ in the EZC group, indicating a statistically significant difference ( $<<0.05$; Table 3$)$. In addition, the Ra value of surface roughness was higher in the EZC group than in the NZC group (Table 4). These results show that the bonding strength of colored zirconia is weaker than that of conventional white zirconia when compared with the results of previous studies.

Although the fracture pattern does not always coincide with the result value of the bond strength, this experiment shows that many cohesive fracture patterns occurred in the NZC group and mixed fracture patterns were achieved in the EZC group (Fig. 4 6). If the bonding strength between the colored zirconia and the veneering porcelain is higher than the veneering porcelain fracture strength, a mixed fracture pattern is shown. In this case, it is difficult to accurately discuss the relationship between the fracture pattern and the bonding strength value, but it can be judged that the phase transition due to the etching process lowered the mechanical strength and showed such fracture tendency. The specimens used in this experiment did not reflect the clinical shape of the dental prosthesis, and there were also limitations in not considering the situation in the oral cavity. In order to obtain more effective results, it is judged that an experimental study or clinical study that reproduces the oral environment is necessary.

The result of this study is the initial shear bonding strength, and there is no study report on the bonding mechanism or long-term stability of this method yet. Therefore, additional studies on thermal cycling experiments and cyclic loading on 
changes in bonding strength under oral function are needed.

\section{CONCLUSIONS}

In this study, to evaluate the bonding strength according to the surface treatment between colored zirconia and veneering porcelain, the upper porcelain was layered using veneering porcelain on the colored zirconia specimen, and shear bonding strength was measured under the conditions suggested by ISO TR 11405 . As a result of checking and comparing fracture patterns, the following conclusions were obtained.

1. As a result of shear bonding strength analysis, the EZC group was $25.95 \pm 2.34 \mathrm{Mpa}$, which was higher than that of the NZC $20.31 \pm 2.32 \mathrm{Mpa}$, and there was a statistically significant difference $(\mathrm{p}<0.05)$.

2. The surface roughness Ra value was higher in the EZC group than in the NZC group.

3. As for fracture patterns, cohesive fractures were dominant in the NZC group, while adhesive fractures and cohesive fractures were mixed in the EZC group.

\section{CONFLICT OF INTEREST}

No potential conflict of interest relevant to this article was reported.

\section{ORCID}

SA-Hak Kim, https://orcid.org/0000-0002-5893-6413

Chong-Kyen Kim, https://orcid.org/0000-0002-6365-172X

\section{REFERENCES}

1. McLean JW, Hughes TH. The reinforcement of dental porcelain with ceramic oxides. Br Dent J. 1965;119:251267.

2. Luthardt R, Weber A, Rudolph H, Schöne C, Quaas S, Walter M. Design and production of dental prosthetic restorations: basic research on dental CAD/CAM technology. Int J Comput Dent. 2002;5:165-176.

3. Kim MJ, Oh SH, Kim JH, Ju SW, Seo DG, Jun SH, et al. Wear evaluation of the human enamel opposing different Y-TZP dental ceramics and other porcelains. J Dent.
2012;40:979-988.

4. Tinschert J, Natt G, Mautsch W, Spiekermann H, Anusavice KJ. Marginal fit of alumina-and zirconia-based fixed partial dentures produced by a CAD/CAM system. Oper Dent. 2001;26:367-374.

5. Denry I, Kelly JR. State of the art of zirconia for dental applications. Dent Mater. 2008;24:299-307.

6. Thompson JY, Stoner BR, Piascik JR, Smith R. Adhesion/ cementation to zirconia and other non-silicate ceramics: where are we now? Dent Mater. 2011;27:71-82.

7. Aboushelib MN, Kleverlaan CJ, Feilzer AJ. Microtensile bond strength of different components of core veneered all-ceramic restorations. Part II: zirconia veneering ceramics. Dent Mater. 2006;22:857-863.

8. Aboushelib MN, Kleverlaan CJ, Feilzer AJ. Effect of zirconia type on its bond strength with different veneer ceramics. J Prosthodont. 2008;17:401-408.

9. Potiket N, Chiche G, Finger IM. In vitro fracture strength of teeth restored with different all-ceramic crown systems. J Prosthet Dent. 2004;92:491-495.

10. Strub JR, Beschnidt SM. Fracture strength of 5 different all-ceramic crown systems. Int J Prosthodont. 1998;11:602-609.

11. Dérand P, Dérand T. Bond strength of luting cements to zirconium oxide ceramics. Int J Prosthodont. 2000;13: 131-135.

12. Tada K, Sato T, Yoshinari M. Influence of surface treatment on bond strength of veneering ceramics fused to zirconia. Dent Mater J. 2012;31:287-296.

13. Kosmac T, Oblak C, Jevnikar P, Funduk N, Marion L. The effect of surface grinding and sandblasting on flexural strength and reliability of Y-TZP zirconia ceramic. Dent Mater. 1999;15:426-433.

14. Phark JH, Duarte S Jr, Blatz M, Sadan A. An in vitro evaluation of the long-term resin bond to a new densely sintered high-purity zirconium-oxide ceramic surface. J Prosthet Dent. 2009;101:29-38.

15. Zarone F, Sorrentino R, Vaccaro F, Traini T, Russo S, Ferrari M. Acid etching surface treatment of feldspathic, alumina and zirconia ceramics: a micromorphological SEM analysis. Int Dent S Afr. 2006;8:20-26.

16. Devigus A, Lombardi G. Shading Vita In-ceram YZ substructures: influence on value and chroma, part II. Int J 
Comput Dent. 2004;7:379-388.

17. Shah K, Holloway JA, Denry IL. Effect of coloring with various metal oxides on the microstructure, color, and flexural strength of 3Y-TZP. J Biomed Mater Res B Appl Biomater. 2008;87:329-337. 